\title{
Southern hemispheric halon trends and global halon emissions, 1978-2011
}

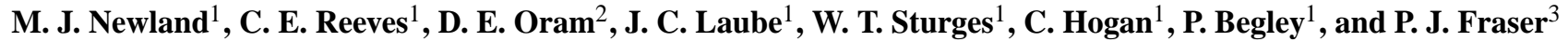 \\ ${ }^{1}$ School of Environmental Sciences, University of East Anglia, Norwich, UK \\ ${ }^{2}$ National Centre for Atmospheric Science, School of Environmental Sciences, University of East Anglia, Norwich, UK \\ ${ }^{3}$ Centre for Australian Weather and Climate Research, CSIRO Marine and Atmospheric Research, Aspendale, \\ Victoria, Australia
}

Correspondence to: M. J. Newland (m.newland@uea.ac.uk)

Received: 10 September 2012 - Published in Atmos. Chem. Phys. Discuss.: 13 November 2012

Revised: 26 April 2013 - Accepted: 29 April 2013 - Published: 6 June 2013

\begin{abstract}
The atmospheric records of four halons, $\mathrm{H}-1211$ $\left(\mathrm{CBrClF}_{2}\right), \mathrm{H}-1301\left(\mathrm{CBrF}_{3}\right), \mathrm{H}-2402\left(\mathrm{CBrF}_{2} \mathrm{CBrF}_{2}\right)$ and $\mathrm{H}-$ $1202\left(\mathrm{CBr}_{2} \mathrm{~F}_{2}\right)$, measured from air collected at Cape Grim, Tasmania, between 1978 and 2011, are reported. Mixing ratios of H-1211, H-2402 and H-1202 began to decline in the early to mid-2000s, but those of H-1301 continue to increase up to mid-2011. These trends are compared to those reported by NOAA (National Oceanic and Atmospheric Administration) and AGAGE (Advanced Global Atmospheric Experiment). The observations suggest that the contribution of the halons to total tropospheric bromine at Cape Grim has begun to decline from a peak in 2008 of about $8.1 \mathrm{ppt}$. An extrapolation of halon mixing ratios to 2060 , based on reported banks and predicted release factors, shows this decline becoming more rapid in the coming decades, with a contribution to total tropospheric bromine of about $3 \mathrm{ppt}$ in 2060. Top-down global annual emissions of the halons were derived using a two-dimensional atmospheric model. The emissions of all four have decreased since peaking in the late 1980s-mid-1990s, but this decline has slowed recently, particularly for H-1301 and H-2402 which have shown no decrease in emissions over the past five years. The UEA (University of East Anglia) top-down model-derived emissions are compared to those reported using a top-down approach by NOAA and AGAGE and the bottom-up estimates of HTOC (Halons Technical Options Committee). The implications of an alternative set of steady-state atmospheric lifetimes are discussed. Using a lifetime of $14 \mathrm{yr}$ or less for $\mathrm{H}$ 1211 to calculate top-down emissions estimates would lead to small, or even negative, estimated banks given reported
\end{abstract}

production data. Finally emissions of H-1202, a product of over-bromination during the production process of $\mathrm{H}-1211$, have continued despite reported production of $\mathrm{H}-1211$ ceasing in 2010. This raises questions as to the source of these H-1202 emissions.

\section{Introduction}

Halons were produced from the 1950s until the end of 2009 and are used mainly in fire extinguishing equipment and explosion protection applications because of their highly inert chemical nature. The two main halons produced for these purposes were $\mathrm{H}-1211\left(\mathrm{CBrClF}_{2}\right)$ and $\mathrm{H}-1301\left(\mathrm{CBrF}_{3}\right)$. A third halon, $\mathrm{H}-2402\left(\mathrm{CBrF}_{2} \mathrm{CBrF}_{2}\right)$, was produced and used mainly in the Soviet Union (McCulloch, 1992). H-1202 $\left(\mathrm{CBr}_{2} \mathrm{~F}_{2}\right)$ is thought to have had very little direct use but was produced as a by-product from over-bromination during $\mathrm{H}$ 1211 manufacture (HTOC, 1999).

The halons have relatively long atmospheric lifetimes $(\mathrm{H}-$ 1211 - 16 yr; H-1301 - 65 yr; H-2402 - 20 yr; H-1202 $2.9 \mathrm{yr}$ (Montzka et al., 2011)). The main atmospheric loss is by photolysis. This occurs almost entirely in the troposphere for $\mathrm{H}-1202$, in both the troposphere and the stratosphere for H-1211 and H-2402, and almost entirely in the stratosphere for $\mathrm{H}-1301$. The bromine released from breakdown in the stratosphere contributes to stratospheric ozone depletion, with bromine being 60-65 times more effective than chlorine at depleting ozone on a per molecule basis (Daniel et al., 2007). Because of this, production of halons 
for non-essential use in non-Article 5 countries (i.e. North America, Europe, Australia and Japan) was banned under the Montreal Protocol in 1994, and production for use in Article 5 countries was banned from 1 January 2010 (HTOC, 2011). The People's Republic of China stopped production of H1211 by the end of 2005 and H-1301 by the end of 2009, and the Republic of Korea halted production of both by the end of 2009 (HTOC, 2011). There is still some limited production of $\mathrm{H}-1301$ for use as a chemical feedstock in the preparation of the fertilizer Fipronil (HTOC, 2011), which is not controlled under the Montreal Protocol. Halons continue to be released to the atmosphere from the existing installed capacity and from users with critical use exemptions (CUEs) such as civil aviation and military applications. Significant halon supply for CUE comes from recycling (HTOC, 2011).

Previous studies of the halons in air extracted from deep firn snow (Butler et al., 1999; Sturrock et al., 2002; Reeves et al., 2005) have shown them to be entirely anthropogenic in origin with concentrations near zero in the early 1960s. Atmospheric mixing ratios of the halons increased rapidly from the late 1970s up to the late 1990s (Butler et al., 1999; Fraser et al., 1999; Sturrock et al., 2002). They have since levelled off or begun to decline, with the exception of $\mathrm{H}$ 1301 which continues to grow (based on data reported up to 2008) (Reeves et al., 2005; Montzka et al., 2011).

The contribution from the halons to total tropospheric bromine was $8.2-8.5 \mathrm{ppt}$ in 2008 , with a similar amount being contributed by methyl bromide (Montzka et al., 2011).

This paper reports atmospheric measurements from Cape Grim, Tasmania, from 1978 up to 2011, updating the record reported in Fraser et al. (1999), and compares the measurements from 1998 to 2011 to similar measurements by NOAA (National Oceanic and Atmospheric Administration) and AGAGE (Advanced Global Atmospheric Gases Experiment; Prinn et al., 2000). A two-dimensional atmospheric chemical transport model is used to derive top-down global annual emissions of the halons. These derived emissions are compared to those derived by NOAA and AGAGE using a top-down approach and by HTOC (Halons Technical Options Committee) using a bottom-up approach. The paper also considers the source of H-1202. The values of the lifetimes of the four halons used to calculate the top-down emissions, and the effect that uncertainties in these values have on the estimated halon banks, are investigated. Finally the current and future contribution of the halons to tropospheric bromine mixing ratios is discussed.

\section{Analytical methods}

\subsection{Sampling}

One hundred and twenty-two (122) samples collected at Cape Grim, Tasmania $\left(40.4^{\circ} \mathrm{S}, 144.4^{\circ} \mathrm{E}\right)$, have been analysed at the University of East Anglia (UEA) for the 4 major halons $(1211,1301,2402,1202)$. Prior to 1993 these samples were predominantly sub-samples of the Cape Grim air archive (see Fraser et al., 1999) but from 1994 onwards are from flask samples collected directly at Cape Grim. These latter samples were collected in either electropolished

(Rasmussen) or silcosteel-treated (Restek) stainless steel canisters and were only taken during baseline atmospheric conditions (with prevailing winds from the south-westerly sector) so as to be representative of background conditions rather than sampling air coming from the landmasses of mainland Australia or Tasmania (Fraser et al., 1991; Weeks et al., 1992; Langenfelds et al., 1996). As discussed in Fraser et al. (1999), we are confident that the Cape Grim archive contains representative samples of background air and that the halons (and many other halocarbons) can be stored without significant changes to their concentrations.

\subsection{Analysis}

All Cape Grim samples collected between 1978 and the end of 2004 (94 samples) were analysed using an Agilent 5890 gas chromatograph coupled to a trisector mass spectrometer (GC-MS; V.G./Micromass Autospec) operated in single ion, electron ionisation mode. During this period the halon gases were separated on $\mathrm{KCl}$-passivated alumina $\left(\mathrm{Al}_{2} \mathrm{O}_{3} / \mathrm{KCl}\right)$ PLOT columns (see Fraser et al., 1999, for further details). Since 2005, all samples (25) have been analysed using a similar method but with an updated GC-MS instrument (Waters Autospec Premier/Agilent 6890 GC), a slightly modified pre-concentration procedure (as described by Oram et al., 2012) and an Agilent GS GasPro column (see Laube et al., 2010, for further details).

The current GasPro/Autospec-Premier combination has also been used to reanalyse selected samples (21) collected prior to 2005 to ensure comparability with the original record measured using the Al-PLOT/Autospec combination. This analysis appears to show a small, unexplained non-linearity at low mixing ratios for $\mathrm{H}-1211$ and $\mathrm{H}-2402$ which affects the earlier (pre-1989) part of the record (see the Supplement). During the first analytical period (samples collected between 1978 and 2004) different Al-PLOT columns were used for the Cape Grim analyses. Initially these were supplied by Chrompak and subsequently by Agilent. In 2004 seven samples, collected during the period 1978-1993, were reanalysed on the Agilent Al-PLOT column, and these show very good agreement with the more recent GasPro measurements, suggesting that the non-linearity does not stem from the analytical system itself. The non-linearity appears to stem from one particular Chrompak Al-PLOT column and is only evident in measurements made using this column on samples collected prior to 1989 (and only for H-1211 and H-2402). Indeed a static dilution series derived from a background air sample (see Laube et al., 2012) and analysed with the current GasPro setup showed no detectable non-linearity. Consequently we have excluded the sub-set of pre-1989 H-1211 and H-2402 
data which were analysed on the suspect Al-PLOT column. All Cape Grim data, with the relevant analytical details, are shown in Table S2 of the Supplement.

The mean precisions of the measurements of the four halons were $2.2 \%(\mathrm{H}-1301), 1.2 \%(\mathrm{H}-1211), 3.7 \%(\mathrm{H}-$ $1202)$ and $2.1 \%(\mathrm{H}-2402)$.

\subsection{Calibrations}

The measurements of $\mathrm{H}-1211$ and $\mathrm{H}-1301$ are presented on the NOAA Climate Monitoring and Diagnostics Laboratory (NOAA-CMDL) NOAA-2006 gravimetric scale; the H-1301 calibration is based on GC-MS analyses (S. Montzka, personal communication, 2012), for ease of comparison with the most recent reported measurements and emissions in Montzka et al. (2011). To convert from the UEA volumetric scales, used in previous work, to the NOAA-2006 gravimetric scales, H-1211 mixing ratios are multiplied by 1.19 and $\mathrm{H}-1301$ mixing ratios are multiplied by 0.89 . H-1202 and H2402 are presented on the UEA volumetric scale (see Fraser et al., 1999 for details of standard preparation). The uncertainties for the NOAA-2006 gravimetric scale are estimated as $1 \%$ for $\mathrm{H}-1211$ and $2 \%$ for $\mathrm{H}-1301$ (Brad Hall, personal communication), those of the UEA volumetric scale are estimated as $4 \%$ for both H-2402 and H-1202 (Fraser et al., 1999).

The AGAGE data are presented on the SIO-2005 scale (Scripps Institute of Oceanography).

\subsection{Atmospheric modelling}

\subsubsection{Model transport and chemistry}

The chemical transport model used is two dimensional with twenty-four equal-area latitudinal bands and twelve equalheight vertical layers extending to an altitude of $24 \mathrm{~km}$. The atmospheric circulation used in the model is that derived by Plumb and Mahlman (1987). The absorption cross-sections are calculated for each grid box as a function of seasonally varying temperature for the wavelengths $200-400 \mathrm{~nm}$. They are the mean of the temperature-dependent absorption crosssections reported by Gillotay and Simon (1989), Gillotay et al. (1988) and Burkholder et al. (1991). Note that this is different to Fraser et al. (1999) in which a function, defined by Sander et al. (1994), was used which represented a combination of the cross-sections reported by Gillotay and Simon (1989), Gillotay et al. (1988) and Burkholder et al. (1991). However this function has not appeared in more-recent reports, and Sander et al. (2011) just present the functions defined by Gillotay and Simon (1989), Gillotay et al. (1988) and Burkholder et al. (1991). This difference accounts for the slight difference between the lifetimes calculated in Fraser et al. (1999) and those calculated in this work (see Sect. 8).

The $\mathrm{OH}$ values are input monthly and interpolated in between these times for each grid cell using a sine smooth- ing function. The $\mathrm{OH}$ field is based on modelling by Hough (1991) and has then been adjusted to give a lifetime for methyl chloroform with respect to reaction with $\mathrm{OH}$ of $6.1 \mathrm{yr}$, as given by the most recent WMO review (Montzka et al., 2011), using a reaction rate of $1.2 \times 10^{-12} \mathrm{e}^{(-1440 / T)}$ (Atkinson et al., 2008).

The diffusive loss of gases from the top of the model is governed by defining the ratio, $F$, of the concentration of the species in the top box of the model $(23 \mathrm{~km})$ to that of a box directly above the model domain $(25 \mathrm{~km})$. The value of this ratio was adjusted for $\mathrm{H}-1211, \mathrm{H}-1301$ and $\mathrm{H}-2402$ so that, in combination with the loss from photolysis and reaction with $\mathrm{OH}$, the steady-state lifetimes of the halons within the model domain were equal to those given in Montzka et al. (2011) (H-1211 - 16 yr; H-1301 - 65 yr; H-2402 - 20 yr). To achieve these steady-state lifetimes, values of 0.952 (H-1211), 0.736 $(\mathrm{H}-1301)$ and $0.820(\mathrm{H}-2402)$ were used for the ratio $F$. For $\mathrm{H}-1202$, the lifetime reported in Montzka et al. (2011) was originally derived by Fraser et al. (1999) using the model used in this work. However due to changes in the calculation of absorption cross-sections (discussed above), the lifetime of $\mathrm{H}-1202$ within the model domain is revised to $2.6 \mathrm{yr}$.

\subsubsection{Emissions}

The model has two main adjustable input functions, the total global annual emissions and the latitudinal distribution of these emissions.

The latitudinal distribution of halon production changed considerably during the early-mid-1990s when the Montreal Protocol came into force, banning the further production of halons in non-Article 5 countries. The major area of production since 1994 has been South-East Asia, namely China (HTOC, 2011). However the emission distribution would not have changed so dramatically since the use of halons for fire protection applications was phased out gradually in nonArticle 5 countries with some use for critical exemptions still on-going.

$\mathrm{H}-2402$ was produced almost exclusively in Russia and former Soviet countries (HTOC, 2011). Emissions of H-2402 are now limited largely to these countries and to countries which use ex-Soviet military equipment.

The emissions distributions used in the model for H-1211 and $\mathrm{H}-1301$ were varied according to the reported regional annual emissions of these halons in HTOC (2011). The distribution used for $\mathrm{H}-1202$ emissions was the same as that of $\mathrm{H}-1211$ given that $\mathrm{H}-1202$ is a by-product of $\mathrm{H}-1211$ production (see Sect. 7). H-2402 emissions were assumed to have a constant distribution throughout the period over which the model was run.

The annual emissions input to the model were adjusted manually so that the model output for the box representing $35.7^{\circ} \mathrm{S}-41.8^{\circ} \mathrm{S}$ simulated mixing ratios comparable to the measurements from Cape Grim $\left(40.4^{\circ} \mathrm{S}\right)$. The model has previously been shown to reproduce southern 
Table 1. Mean mixing ratios of the halons at Cape Grim for January to June 2011, and mean growth rates for the periods 1985-1999, 1999-2005 and 2005-2011.

\begin{tabular}{ccccc}
\hline & Mean mixing ratio & \multicolumn{3}{c}{ Mean growth rate $\left(\mathrm{ppq} \mathrm{yr}^{-1}\right)$} \\
& Jan-Jun 2011 (ppt) & $1985-1999$ & $1999-2005$ & $2005-2011$ \\
\hline H-1211 & $3.98 \pm 0.04$ & $186 \pm 14$ & $67 \pm 24$ & $-42 \pm 16$ \\
H-1301 & $3.15 \pm 0.03$ & $139 \pm 7$ & $54 \pm 21$ & $29 \pm 17$ \\
H-2402 & $0.39 \pm 0.01$ & $16 \pm 1.5$ & $0 \pm 1.7$ & $-3.3 \pm 2.5$ \\
H-1202 & $0.020 \pm 0.001$ & $2.2 \pm 0.1$ & $-1.7 \pm 0.2$ & $-2.6 \pm 0.2$ \\
\hline
\end{tabular}

hemispheric observations to within about $5 \%$ for gases emitted mostly in the Northern Hemisphere and for which there have been well-reported emission inventories such as CFC11 and CFC-12 (e.g. Reeves et al., 2005).

\section{Cape Grim mixing ratio time series}

The mixing ratios of the four halons measured at Cape Grim between 1998 and 2011 are shown in the main panels of Fig 1, as well as measurements by NOAA and AGAGE at Cape Grim where available. The entire records from Cape Grim (1978-2011) are shown as insets in the main panels. The measurements made using the first analytical method (Al-PLOT column, Autospec) have previously been reported by Fraser et al. (1999) for the period 1978-1998; however the mixing ratios of $\mathrm{H}-1211$ and $\mathrm{H}-1301$ are presented here on the NOAA-2006 gravimetric calibration scale as opposed to the UEA volumetric scale used in Fraser et al. (1999). The measurements made using the first method between 1999 and 2004 and those using the current methods (GasPro column, Autospec-Premier) have not been previously reported. It is evident that the data obtained from the two different analytical setups agree very well and can be combined to make a single continuous record. The Cape Grim measurements and the mean annual mixing ratios from the model fit are available in the Supplement.

Table 1 shows the mean mixing ratios of the halons between January and June 2011 at Cape Grim and the mean growth rates during the periods 1985-1999 (when the mixing ratios were all increasing), 1999-2005 (when growth rates began to slow or turn over) and 2005-2011 (when the mixing ratios of three of the halons were decreasing).

\section{$3.1 \quad H-1211$}

The mixing ratio of H-1211 grew rapidly during the 1980s and 1990s from $1.2-1.4 \mathrm{ppt}$ (parts per trillion) in 1985 to $3.9 \mathrm{ppt}$ at the end of 1999 at an average growth rate of $0.19 \mathrm{ppt} \mathrm{yr}^{-1}$. The growth rate began to slow after 1999 and mixing ratios reached a maximum of 4.2 ppt in 2004-2006. Thereafter the concentrations at Cape Grim began to slowly decline to a mean mixing ratio in the first half of 2011 of $4.0 \mathrm{ppt}$.
NOAA reports a similar trend in mixing ratios for $\mathrm{H}-$ 1211 from measurements by GC-MS of Cape Grim background samples (mean of flask pairs) between 1998 and mid2011 (Montzka and Elkins, 2012). These measurements are about 1\% higher than UEA measurements between 1998 and 2003 and about $1 \%$ lower between 2003 and 2011. The mixing ratios reported by AGAGE from in situ baseline measurements by GC-MS at Cape Grim since 1998 (http://agage.eas.gatech.edu) display a similar trend to those reported here but are consistently about 2-3\% higher. This is most likely caused by differences in calibration scales (see Sect. 2.2.2).

\section{$3.2 \quad H-1301$}

The H-1301 mixing ratio grew steadily from a mean of 0.7$0.8 \mathrm{ppt}$ in 1985 to a mean of $2.6-2.7 \mathrm{ppt}$ in 1999 at an average growth rate of $0.14 \mathrm{ppt} \mathrm{yr}^{-1}$. The mean mixing ratio in the first half of 2011 was 3.15 ppt with a mean growth rate since 2000 of $0.045 \mathrm{ppt} \mathrm{yr}^{-1}$. H-1301 is the only one of the halons reported here to have atmospheric mixing ratios that are still increasing. This continued growth is consistent with predictions in Fraser et al. (1999) and Montzka et al. (2003) which show H-1301 mixing ratios peaking around 2020 before beginning to decline.

The mixing ratios reported by NOAA from GC-ECD (electron capture detection) measurements on Cape Grim flask pair mean samples are almost $5 \%$ higher than those of UEA between 1998 and 2000 but then steadily converge with those reported here during 2001 and 2002, and from 2003 the two trends are virtually identical up to the middle of 2006 when NOAA's ECD measurements stopped (Montzka and Elkins, 2012). Since 2004 NOAA has also measured the flask samples by GC-MS. These mixing ratios agree very well with those reported here (S. Montzka, personal communication, 2012). The baseline mixing ratios reported by AGAGE since 1998, measured by GC-MS in situ at Cape Grim (http://agage.eas.gatech.edu/), are consistently about $3 \%$ higher than those reported here (presumably caused by differences in the calibration scales) with the exception of a period between 2001 and 2003 during which the AGAGE measurements show a high degree of variability. 

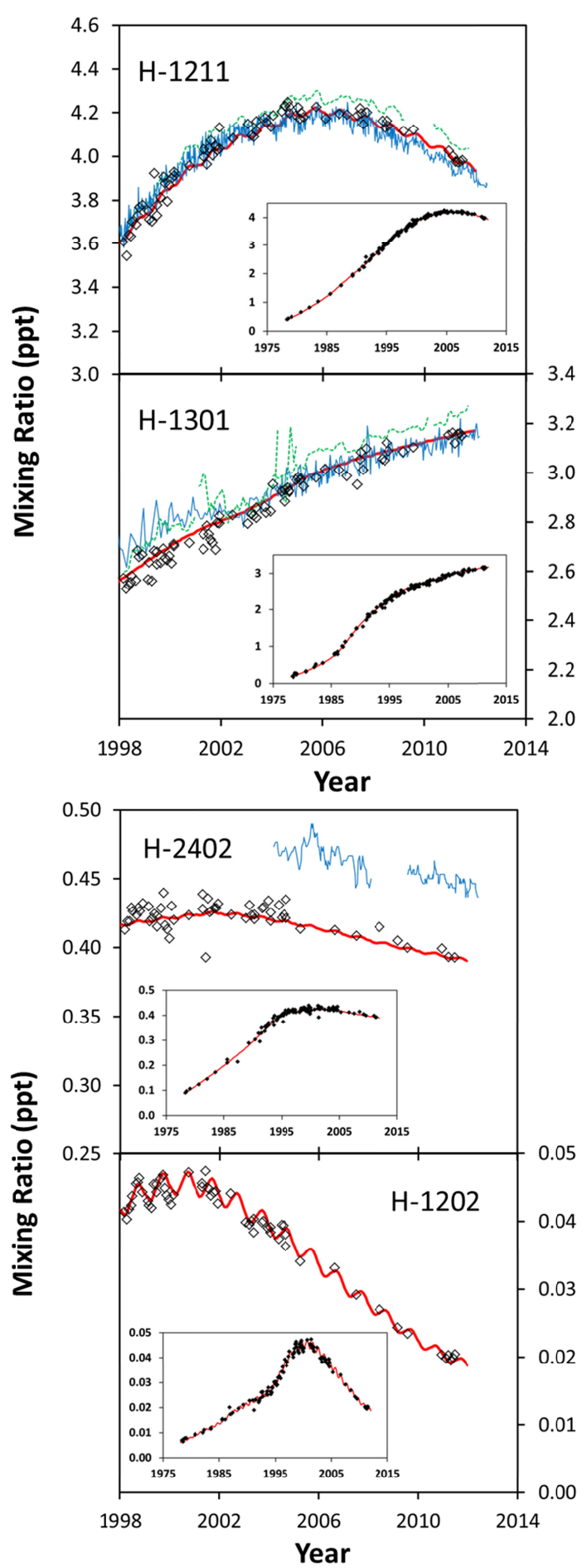

Fig. 1. Measured mixing ratios (ppt) of the halons from Cape Grim at UEA from 1998 to 2011 (open black diamonds). Solid red lines are the model runs used to derive emissions. Solid blue lines for $\mathrm{H}-$ 1211, H-1301 and H-2402 are measured mixing ratios (ppt) from Cape Grim by NOAA (Montzka and Elkins, 2012). Dashed green lines for $\mathrm{H}-1211$ and $\mathrm{H}-1301$ are measured mixing ratios (ppt) from Cape Grim by AGAGE (http://agage.eas.gatech.edu). Inset panels show the complete UEA record from Cape Grim from 1978 to 2011 (solid black diamonds).

\section{$3.3 \quad \mathrm{H}-2402$}

The mixing ratio of $\mathrm{H}-2402$ increased from about $0.21 \mathrm{ppt}$ in 1985 to a mean of $0.42 \mathrm{ppt}$ in 1999 at a mean growth rate of $0.016 \mathrm{ppt} \mathrm{yr}^{-1}$. The mixing ratio levelled off during the late 1990 s-early 2000 s at a peak of $0.42-0.44$ ppt. It began to fall around 2005 and reached a mean of 0.39 ppt during the first half of 2011.

NOAA reports measurements of $\mathrm{H}-2402$ from 2004 onwards and for a brief period from 1995 to the start of 1997. The declining trend since 2004 agrees well with the trend observed in this work, but the mixing ratios reported by NOAA are consistently $10-15 \%$ higher. This is again probably caused by a calibration difference since the UEA measurements are presented on the UEA volumetric scale.

AGAGE H-2402 data are not currently available from the publically accessible data archive (http://agage.eas.gatech. edu), but monthly global means were presented in Montzka et al. (2011) and are very similar to those reported by NOAA in Montzka et al. (2011).

\section{$3.4 \quad \mathrm{H}-1202$}

The mixing ratio of H-1202 at Cape Grim grew from an annual mean of 14-15 ppq (parts per quadrillion) in 1985 to a mean of $45 \mathrm{ppq}$ in 1999 with a mean growth rate of $2.2 \mathrm{ppq} \mathrm{yr}^{-1}$. The mean annual mixing ratio remained fairly stable between 1999 and 2001 and has since fallen sharply to a mean mixing ratio of about $20 \mathrm{ppq}$ in the first half of 2011 .

UEA is the only institution to have reported measurements of $\mathrm{H}-1202$.

\section{Model-derived emissions}

The annual global emissions of the halons, as derived from the model runs in Fig. 1, are shown in Fig. 2. Also shown, where available, are the emissions reported by NOAA and AGAGE (Montzka et al., 2011), both derived using a onebox atmospheric model with global measurements, and the emissions derived using a 12-box model in conjunction with AGAGE measurements (from the Cape Grim archive air before 2004 and global measurements thereafter (Montzka and et al., 2011)). Finally the bottom-up estimates of HTOC are shown (HTOC, 2011); these emission estimates are calculated based on emissions modelling, taking into account industry-reported production, usage and destruction.

Uncertainties in the measurements and fitting the model output to those measurements, the atmospheric lifetimes of the halons, and in the model transport all contribute to uncertainties in the model-derived emissions. Figure 2 shows the annual emissions estimated in this work with error bars based on the measurement errors associated with each individual data point (see Supplement) and errors in the transport within the model (which are taken as a constant $5 \%$ throughout the run based on previous work with the model (e.g. Reeves et 
Table 2. Estimates of the cumulative emissions of the halons between 1963 and 2010 reported by HTOC (bottom-up estimate) and calculated in this work using firstly the lifetimes reported by Montzka et al. (2011) and secondly the alternative lifetimes calculated in this work (Sect. 8). Also shown are the banks of H-1211 and H-1301 that are calculated by subtracting the specific estimates of the cumulative emission from the estimates of cumulative production as reported by HTOC (HTOC, 2011).

\begin{tabular}{|c|c|c|c|c|c|c|}
\hline \multicolumn{7}{|c|}{ Using $\tau_{\mathrm{atm}}$ Montzka et al. (2011) ${ }^{\mathrm{a}}$} \\
\hline & \multicolumn{4}{|c|}{ Cumulative emissions (Gg) } & \multicolumn{2}{|c|}{ Banks (Gg) } \\
\hline Reference & H-1211 & H-1301 & H-2402 & H-1202 & H-1211 & H-1301 \\
\hline This Work & 276 & 106 & 42 & 16 & 37 & 43 \\
\hline HTOC & 248 & 106 & - & - & 65 & 43 \\
\hline \multicolumn{7}{|l|}{ Using alternative $\tau_{\mathrm{atm}}{ }^{\mathrm{b}}$} \\
\hline & \multicolumn{4}{|c|}{ Cumulative emissions (Gg) } & \multicolumn{2}{|c|}{ Banks (Gg) } \\
\hline & H-1211 & H-1301 & H-2402 & H-1202 & H-1211 & H-1301 \\
\hline Using alternative $\tau_{\mathrm{atm}}$ & 290 & 101 & 46 & 16 & 24 & 48 \\
\hline Uncertainty range & 262-319 & 99-103 & $42-49$ & $13-19$ & $-5-52$ & $47-50$ \\
\hline
\end{tabular}

a Except H-1202 (lifetime from this work).

b See Sect. 8 and Table 4.

al. 2005)). These errors should allow comparison with other top-down-derived emissions (i.e. NOAA and AGAGE), assuming that similar atmospheric lifetimes were used. Errors associated with the lifetimes of the halons are not shown in Fig. 2; a discussion of lifetimes and uncertainties is presented in Sect. 8.

\section{$4.1 \quad H-1211$}

The model-derived annual emissions of $\mathrm{H}-1211$ are $3.0 \mathrm{Gg}$ in 1978; they then increase at an average growth rate of $0.58 \mathrm{Gg} \mathrm{yr}^{-1}$ to maximum emissions of $12.8 \mathrm{Gg}$ in 1995 . Emissions have since decreased at an average rate of $0.52 \mathrm{Gg} \mathrm{yr}^{-1}$ to $5.0 \mathrm{Gg}$ in 2010 .

The emissions derived here show a similar trend to those derived by NOAA and AGAGE. The cumulative emissions derived from the model for the period 1979-2009, shown in Table 2, are $253 \mathrm{Gg}$, compared to those using the AGAGE measurements and a 12-box model which are $11 \%$ lower at $225 \mathrm{Gg}$. The emissions reported by HTOC are similar to those reported here with cumulative emissions for the period 1979-2009 of $234 \mathrm{Gg}, 8 \%$ lower than those derived in this work and $4 \%$ higher than those derived by AGAGE.

\section{$4.2 \quad H-1301$}

The model-derived annual emissions of H-1301 in 1978 are $1.5 \mathrm{Gg}$. Annual emissions then increase gradually to $2.5 \mathrm{Gg}$ in 1984 at an average rate of $0.17 \mathrm{Gg} \mathrm{yr}^{-1}$ before a more rapid increase up to a maximum of $6.0 \mathrm{Gg}$ in 1987 at a rate of $1.2 \mathrm{Gg} \mathrm{yr}^{-1}$. They then decline steadily to annual emissions between 2007 and 2010 of $1.8-1.9 \mathrm{Gg}$.

The NOAA record shows a great deal of variability, and, though it agrees with the general decline in recent years, the exact features are often quite different. The AGAGE emissions display far less variability and a more similar trend. Emissions derived by both AGAGE and HTOC display a steady rise from 1978 to the mid-late 1980s, whereas we derive a slower growth in the early 1980s followed by a steep increase beginning around 1985. This was also commented on in Fraser et al. (1999).

The cumulative emissions derived in this work for the period 1979-2009 (97 Gg) (Table 2) are similar to those of HTOC (99 Gg) and those derived using a 12-box model with AGAGE measurements $(96 \mathrm{Gg})$.

\section{$4.3 \quad \mathrm{H}-2402$}

The model-derived annual emissions are $0.9 \mathrm{Gg}$ in 1978 and increase steadily up to a peak of $1.9 \mathrm{Gg}$ in 1990 at a growth rate of $0.08 \mathrm{Gg} \mathrm{yr}^{-1}$. They then decline to $1.0 \mathrm{Gg}$ in 1996 and remain around this level until 2000. They then begin to decline again to $0.7 \mathrm{Gg}$ in 2006 and have remained around this level up to 2010 .

The emissions derived by AGAGE for the period 19792009 (Table 2) using a 12-box model display a very similar trend and calculate very similar cumulative emissions for the period 1979-2009 of $36 \mathrm{Gg}$ compared to $35 \mathrm{Gg}$ in this work. HTOC does not report annual emissions of H-2402.

\section{$4.4 \quad \mathrm{H}-1202$}

The model-derived annual emissions of $\mathrm{H}-1202$ are $0.16 \mathrm{Gg}$ in 1978. They increase steadily up to $0.52 \mathrm{Gg}$ in 1993 at a rate of $0.024 \mathrm{Gg} \mathrm{yr}^{-1}$ and then increase steeply to a peak of $0.84 \mathrm{Gg}$ in 1997 before declining to $0.26 \mathrm{Gg}$ in 2010 . 


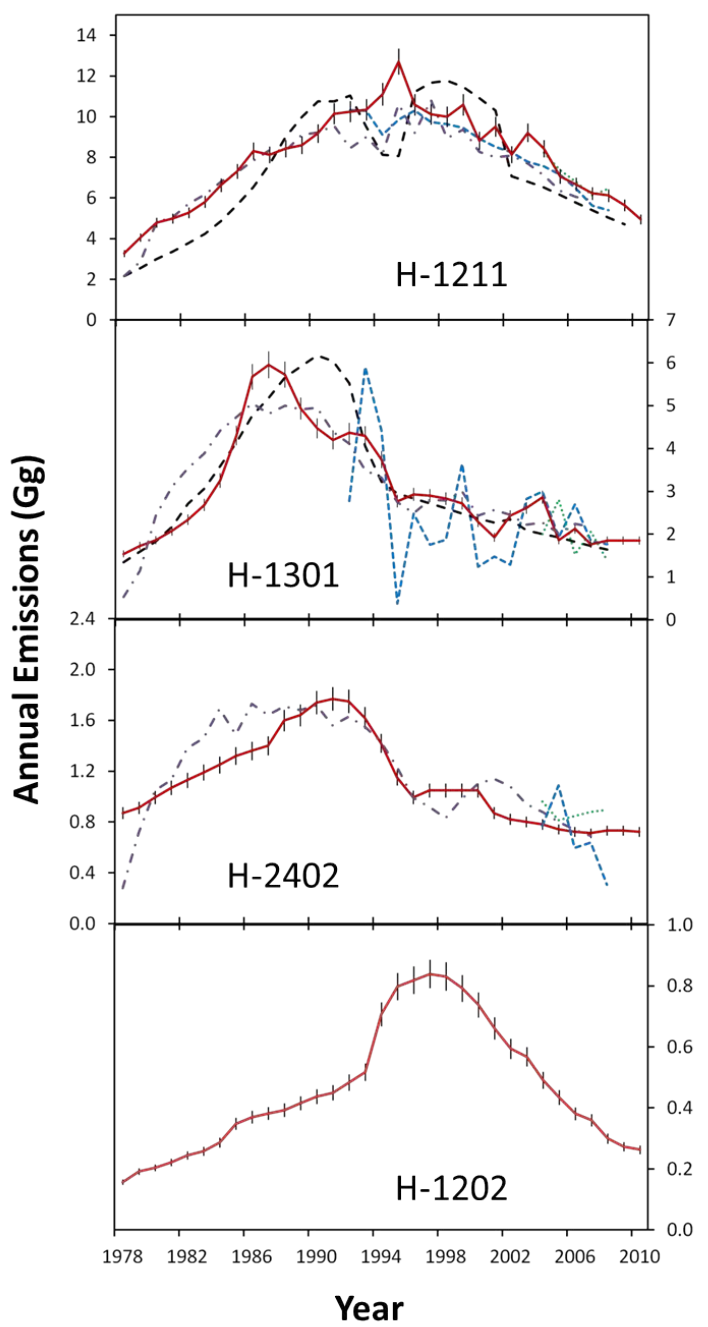

Fig. 2. Model-derived global annual emissions $(\mathrm{Gg})$ of the halons. Current work - red line; NOAA one-box model (Montzka et al., 2011) - blue short dashed line; AGAGE one-box model (Montzka et al., 2011) - green dotted line; AGAGE 12-box model (Montzka et al., 2011) - purple dash-dot line; annual emissions reported by HTOC (2011) - black long dashed line. Uncertainty ranges, as defined in Sect. 4, are shown for each year.

\section{Cumulative emissions and halon banks}

AGAGE reports annual global emissions of $\mathrm{H}-1301, \mathrm{H}-$ 1211 and H-2402 for the years 1979 to 2008 in Montzka et al. (2011). A comparison with the cumulative emissions of $\mathrm{H}-1211$ derived in this work and those from HTOC for the same period shows AGAGE and HTOC to be very similar with emissions of $225 \mathrm{Gg}$ and $229 \mathrm{Gg}$, respectively, while in this work emissions of $248 \mathrm{Gg}$ are derived. For H-1301 HTOC reports emissions of $97 \mathrm{Gg}$, AGAGE of $96 \mathrm{Gg}$ and this work of $95 \mathrm{Gg}$. For H-2402 HTOC does not report emissions, AGAGE reports cumulative emissions of $36 \mathrm{Gg}$ and this work of $35 \mathrm{Gg}$.
Table 2 shows a comparison between the cumulative emissions reported by HTOC and those from this work for the period 1963 to 2010 (this assumes that halon emissions started in 1963, and so these are in effect total cumulative emissions). In the model, emissions prior to 1978 were calculated by assuming a roughly exponential increase from zero in 1963 and adjusted so that the model output for 1978 matched the first Cape Grim measurements. HTOC reports total cumulative emissions of $\mathrm{H}-1211$ of $248 \mathrm{Gg}$ compared to the $276 \mathrm{Gg}$ calculated in this work. For H-1301 HTOC reports total cumulative emissions of $106 \mathrm{Gg}$, the same value is calculated in this work.

"Banks" of halons exist and have not been destroyed since the compounds are required for various critical use exemptions from the Montreal Protocol. Table 2 shows estimates of the size of these banks at the end of 2010, subtracting estimates of total cumulative emissions from the HTOC estimates of cumulative production. Using its bottom-up estimates of the emissions, HTOC (2011) calculates the banks to be $65 \mathrm{Gg}$ and $42.5 \mathrm{Gg}$ for $\mathrm{H}-1211$ and $\mathrm{H}-1301$, respectively. HTOC also independently estimates the $\mathrm{H}-2402$ bank to be $2.3 \mathrm{Gg}$. Table 2 also shows the banks for $\mathrm{H}-1211$ and $\mathrm{H}-$ 1301 calculated using the total cumulative emissions derived in Sect. 4 up to the end of 2010. These are $37 \mathrm{Gg}$ for H-1211, $43 \%$ lower than the value reported by HTOC, and $43 \mathrm{Gg}$ for $\mathrm{H}-1301$, very similar to the value reported by HTOC. The banks of H-2402 and H-1202 cannot be calculated because HTOC does not report their production.

\section{Total tropospheric bromine}

The total bromine mixing ratio from methyl bromide and the halons in the troposphere peaked at 16-17 ppt around 1998 and by 2008 had declined to $15.7 \pm 0.2 \mathrm{ppt}$ (Montzka et al., 2011). This decline has been attributed mainly to a decrease in the emissions of methyl bromide (Montzka et al., 2011). Our measurements from Cape Grim show that during the period 2005-2011 the mixing ratios of $\mathrm{H}-1211, \mathrm{H}-$ 2402 and H-1202 have all fallen while that of $\mathrm{H}-1301$ has risen slightly (Table 1). The contribution to total tropospheric bromine from the halons at Cape Grim peaked at $8.1 \mathrm{ppt}$ between 2007-2008 and has since fallen to $7.9 \mathrm{ppt}$ in the first half of 2011. This peak value of $8.1 \mathrm{ppt}$ is lower than the global surface values of 8.2-8.5 ppt reported in Montzka et al. (2011) for 2005-2008. The difference in peak mixing ratios is likely to be due to calibration differences between UEA and AGAGE and the fact that our numbers are based on southern hemispheric measurements from Cape Grim as opposed to measurements from global networks. The latter would also explain why the peak observed at Cape Grim was slightly later than from the global networks.

Figure $3 \mathrm{a}$ shows the contribution of each of the halons to global mean tropospheric bromine mixing ratios as modelled for the period 1978-2060. From 1978 to 2010 the emissions 


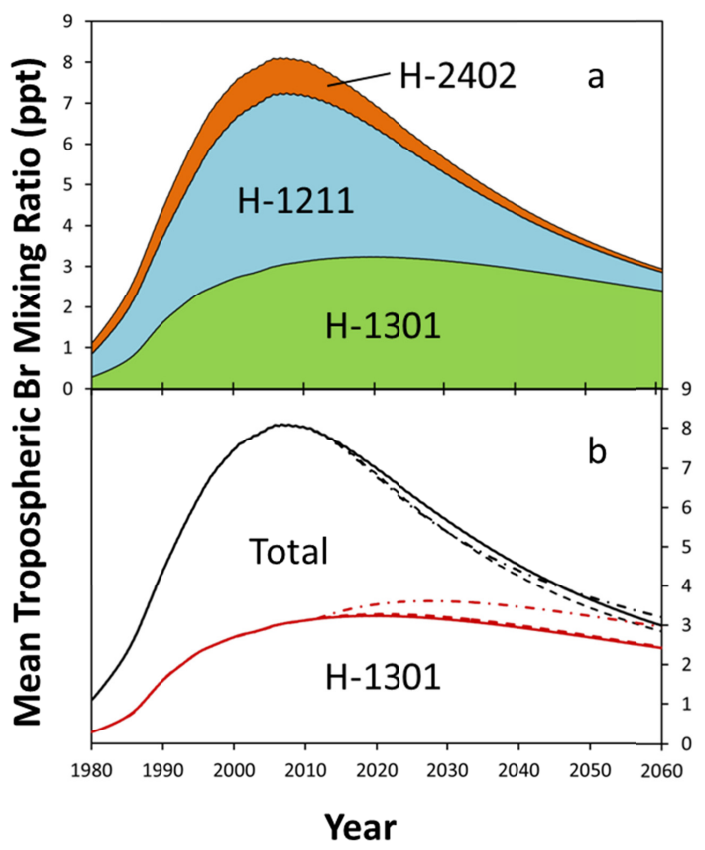

Fig. 3. The contribution of each of the halons to global mean tropospheric bromine mixing ratios as modelled for the period 19782060. From 1978 to 2010 the emissions used to model the halon mixing ratios are those derived in Sect. 4. (a) Emissions after 2010 are based on banks from HTOC (2011) and bank release fractions from Daniel and Velders (2011). (b) Emissions before 2010 are as for Fig. 3a (solid line); emissions after 2010 based on banks and bank release fractions calculated in this work using atmospheric lifetimes reported in Montzka et al. (2011) (dashed line); emissions after 2010 based on banks and bank release fractions calculated in this work using the atmospheric lifetimes calculated in Sect. 8 (dash-dot line).

used to model the halon mixing ratios are those derived in Sect. 4. The emissions after 2010 are based on the reported banks from HTOC (2011) and the bank release fraction (the proportion of the remaining bank released per year) reported in WMO 2010 (H-1211 - 0.075, H-1301 - 0.04, H-2402 0.08) (Daniel and Velders, 2011).

H-1202 is not shown in Fig. 3 as its contribution is negligible due to low emissions and a short lifetime.

It is seen that $\mathrm{H}-1211$ mixing ratios fall rapidly after 2010 and H-1301 contributes more than $50 \%$ of the total tropospheric bromine from halons after 2024 (compared to $39 \%$ in 2010). This is because of its long atmospheric lifetime. By 2060 the contribution of the halons to total tropospheric bromine is predicted to fall to $3.0 \mathrm{ppt}$, more than $80 \%$ of which is from $\mathrm{H}-1301$.

Assuming that production has ceased, these predictions are an upper estimate of the future contribution of the halons to tropospheric bromine since they may be destroyed or consumed in alternative ways, preventing their release to the atmosphere. The rate of decline of tropospheric bromine is de-

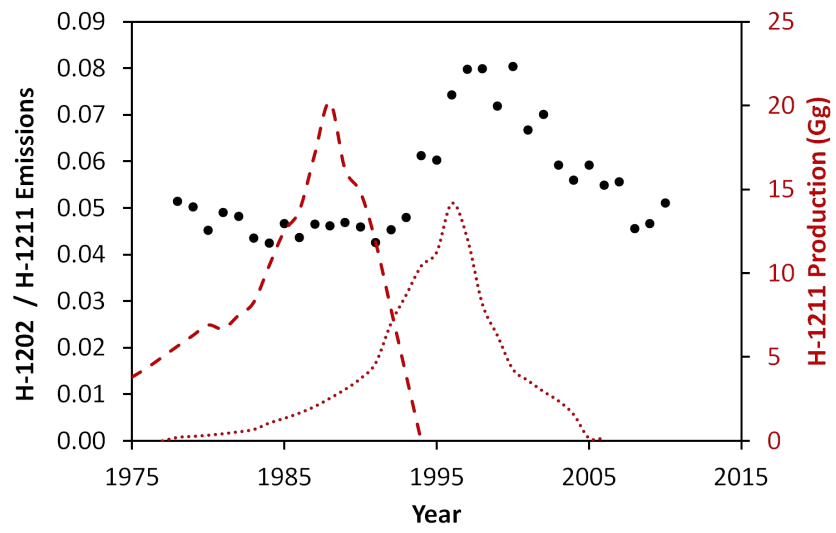

Fig. 4. The ratio of model-derived emissions of H-1202 to H-1211 (see Fig. 2) (black circles). Also shown is production of H-1211 in non-Article 5 countries (red dashed line) and Article 5 countries (red dotted line) (HTOC, 2011).

pendent on the lifetimes of the halons. The effects of possible changes to the recommended lifetimes are discussed in Sect. 8 .

Figure $3 \mathrm{~b}$ also shows (dashed line) the extrapolation to 2060 of the halons' contribution to total tropospheric bromine, using release fractions based on the banks calculated from our top-down cumulative emissions derived using the atmospheric lifetimes of the halons reported in Montzka et al. (2011) (described above in Sect. 5 and Table 2). These bank release fractions for $\mathrm{H}-1211$ and $\mathrm{H}-1301$ were calculated by dividing emissions of the halon in 2010 by the calculated bank at the end of 2009 (H-1211 - 0.12, H-1301 0.044). For H-2402 the same bank and bank release fraction are used because a revised bank cannot be calculated in this work (see Sect. 5). With the smaller H-1211 bank suggested by our top-down emissions estimate, the tropospheric bromine burden from the halons will initially fall more quickly in the coming decades, but by 2060 there will be little difference. Further, with the additionally slightly larger H-1301 bank suggested by our top-down emissions estimate, H-1301 contributes $50 \%$ slightly earlier in 2022, as opposed to 2024, and in $2060 \mathrm{H}-1301$ contributes more than $85 \%$ of the total bromine from the halons.

\section{The source of $\mathrm{H}-1202$}

Figure 2 shows that annual global emissions of $\mathrm{H}-1202$ in 2010 were $0.26 \mathrm{Gg}$. If $\mathrm{H}-1202$ was emitted when $\mathrm{H}-1211$ was produced (eg. Reeves et al., 2005), then emissions should have fallen to zero since the beginning of 2010 when global $\mathrm{H}-1211$ production is reported to have ceased (HTOC, 2011). That emissions have not fallen to zero suggests one of two possibilities: either there is still significant global production of $\mathrm{H}-1211$ or there are other sources of $\mathrm{H}-1202$ emissions that are not directly a result of $\mathrm{H}-1211$ production. 
Reported efficiencies of Chinese $\mathrm{H}-1211$ plants during an audit in 2002 suggested that $0.02-0.03 \mathrm{Gg}$ of $\mathrm{H}-1202$ were produced per Gg of H-1211 (E. Pedersen, World Bank, personal communication, 2002). Based on these figures annual emissions of $0.26 \mathrm{Gg}$ of $\mathrm{H}-1202$ would suggest an unreported global H-1211 production in 2010 on the order of $10 \mathrm{Gg}$ if this were the sole emission source. This seems very unlikely since there has been very little reported $\mathrm{H}-1211$ production since 2005 (Fig. 4) and the reported annual global production only ever reached $23 \mathrm{Gg}$ at its peak in 1988. If the efficiency of $\mathrm{H}-1211$ were such that a greater amount of $\mathrm{H}-1202$ were produced per Gg of H-1211, then a smaller on-going production of $\mathrm{H}-1211$ would be required to sustain the derived H-1202 emissions.

The report by the Halons Technical Options Committee of 1991 (HTOC, 1991) suggests that although there was no specific production of H-1202, some of that which was produced as a by-product during $\mathrm{H}-1211$ production was captured and sold on to the military, at least in the United States, for use as fire protection in engine nacelles of aircraft. Such practices would create a bank of H-1202 and a delay in its release to the atmosphere, which might explain the continued emission of $\mathrm{H}-1202$ after $\mathrm{H}-1211$ production is reported to have ceased. In some countries, where the $\mathrm{H}-1202$ produced during $\mathrm{H}-$ 1211 production had no market, the unwanted by-product may have been immediately vented to the atmosphere.

Another possibility is that the H-1202 was not separated from the H-1211 and that H-1211 was sold with a small contamination of $\mathrm{H}-1202$. This could be tested as part of a future study by analysing existing H-1211-charged fire extinguishers.

Figure 4 shows the ratio of H-1202 emissions to H-1211 emissions (both derived in Sect. 4) between 1978 and 2010. It is interesting to note that for much of the record, in particular the first $15 \mathrm{yr}$, this ratio is fairly consistent at around $0.4-0.5$. The ratio does, however, rise through the 1990s to around 0.8 before declining back to around $0.4-0.5$ by 2008 . If these emission ratios were solely due to contamination of $\mathrm{H}-1211$ with H-1202, this implies a level of contamination of $4 \%$ or above. It should be noted, though, that companies that purchase and recycle H-1211 in the United States and Europe have never seen H-1202 as a contaminant (D. Verdonik, HTOC, personal communication, 2013). However, we have been unable to obtain any information on possible H-1202 contamination in $\mathrm{H}-1211$ produced in China, but this would not explain emissions prior to H-1211 production in China.

The increase in the emission ratio follows the timing of the movement of the majority of $\mathrm{H}-1211$ production from nonArticle 5 countries to Article 5 countries, and the decrease follows the decline in H-1211 production in Article 5 countries. The changes in ratio may be a result of changes in the $\mathrm{H}-1211$ production efficiency, or differences in procedures relating to the capture or venting of $\mathrm{H}-1202$, in part due to the shift in production to Article 5 countries. This would not be incongruous with the assertion of Reeves et al. (2005), based
Table 3. Tropospheric ( $\left.\tau_{\text {trop }}\right)$, stratospheric $\left(\tau_{\text {strat }}\right)$, and total atmospheric $\left(\tau_{\mathrm{atm}}\right)$ lifetimes of the halons. Tropospheric lifetimes vary based on the defined height of the tropopause $\left(Z_{\text {trop }}\right)$, with uncertainties due to $\pm 20 \%$ photolysis rates also given at $Z_{\text {trop }}=14 \mathrm{~km}$. Stratospheric lifetimes vary based on the diffusive loss from the top of the model, which is determined by the ratio of the mixing ratio of the given molecule at $25 \mathrm{~km}$ to that in the top model box $(23 \mathrm{~km})$ $(F)$. Uncertainties due to $\pm 20 \%$ photolysis rates are given for representative values of $F$ for each halon (see Sect. 8).

\begin{tabular}{lcccc}
\hline Model Run & H-1211 & H-1301 & H-2402 & H-1202 \\
\hline \multicolumn{5}{c}{$\tau_{\text {trop }}(\mathrm{yr})$} \\
\hline $\mathrm{Z}_{\text {trop }}=12 \mathrm{~km}$ & 25.6 & $>10000$ & 42.9 & 3.11 \\
$\mathrm{Z}_{\text {trop }}=14 \mathrm{~km}$ & 25.0 & $>10000$ & 40.7 & 3.00 \\
$(\sigma \pm 20 \%)$ & $(21.0-30.9)$ & $(-)$ & $(34.0-50.8)$ & $(2.51-3.72)$ \\
$\mathrm{Z}_{\text {trop }}=16 \mathrm{~km}$ & 24.6 & $>10000$ & 39.1 & 2.92 \\
\hline \multicolumn{5}{c}{$\tau_{\text {strat }}(\mathrm{yr})^{*}$} \\
& \multicolumn{5}{c}{} \\
\hline$F=1.0$ & 50.2 & 370 & 50.0 & 27.2 \\
$F=0.8$ & 39.5 & 75.9 & 39.3 & 24.4 \\
$(\sigma \pm 20 \%)$ & - & $(74.0-78.0)$ & - & - \\
$F=0.5$ & 33.6 & 47.5 & 33.4 & 22.3 \\
$F=0.2$ & 30.9 & 39.5 & 30.7 & 21.2 \\
$(\sigma \pm 20 \%)$ & - & - & $(29.3-32.2)$ & $(19.5-23.3)$ \\
$F=0.0$ & 29.8 & 36.8 & 29.6 & 20.7 \\
$(\sigma \pm 20 \%)$ & $(28.7-31.1)$ & - & - & - \\
\hline
\end{tabular}

* Stratospheric lifetimes are only calculated for $\mathrm{Z}_{\text {trop }}=14 \mathrm{~km}$ (stratospheric lifetimes at $Z_{\text {trop }}=12 \mathrm{~km}$ and $16 \mathrm{~km}$ can be inferred using the total lifetime (Table 4) and the tropospheric lifetime).

on data from both the Northern and Southern Hemispheres, that H-1202 emissions have moved to more southerly latitudes (mainly China and South Korea) since the mid-1990s from the more northerly latitudes of Europe and North America.

\section{Atmospheric lifetimes}

The emissions of H-1211, H-1301 and H-2402 derived in Sect. 4 are based on atmospheric lifetimes for the molecules of 16,65 and $20 \mathrm{yr}$, respectively, as given by Montzka et al. (2011). These lifetimes were all originally derived by Burkholder et al. (1991) using a 1-D photochemical model extending to an altitude of $60 \mathrm{~km}$. There have been various other estimates of the tropospheric, stratospheric and total lifetimes, in particular the recent re-evaluation of the stratospheric lifetimes of $\mathrm{H}-1211$ and $\mathrm{H}-1301$ by Laube et al. (2013). Here we evaluate the atmospheric lifetimes for the halons using the 2-D atmospheric model and considering the stratospheric lifetimes reported in Laube et al. (2013). The implications of such changes on the model-derived emissions and on the sizes of the remaining halon banks are considered in Sect. 8.4. 


\subsection{Tropospheric lifetimes}

The modelled tropospheric lifetimes $\left(\tau_{\text {trop }}\right)$ are calculated by running the model to steady state and then dividing the global atmospheric burden of the molecule by the global emissions. The model was run with the photolysis and $\mathrm{OH}$ sinks only active in the troposphere and the diffusive loss from the top of the model switched off. A range of tropospheric lifetimes were calculated by changing the defined height of the tropopause $\left(Z_{\text {trop }}\right)$. These are shown in Table 3 . The uncertainties associated with the absorption crosssections used were also investigated. The cross-sections measured by Gillotay and Simon (1989), Gillotay et al. (1988) and Burkholder et al. (1991) generally agree to within $10 \%$ at room temperature, though this error tends to increase at wavelengths longer than $265 \mathrm{~nm}$. At low temperatures the agreement is generally within $20 \%$, but again differences tend to increase at wavelengths longer than $265 \mathrm{~nm}$. Tropospheric lifetimes were calculated with the photolysis rates adjusted by $\pm 20 \%$ for $Z_{\text {trop }}=14 \mathrm{~km}$ (Table 3). This estimate is considered to account for both uncertainties in the absorption cross-sections and other uncertainties in the photolysis rates calculated by the model such as the solar photon flux and attenuation of the flux by molecular oxygen and ozone. Errors in the rate constant for reaction with the hydroxyl radical and in the $\mathrm{OH}$ field are not considered since this loss is at least 20 times smaller than photolysis for all four halons.

It is seen that the given height of the tropopause does not affect the calculated tropospheric lifetimes greatly. Moving the tropopause from $12 \mathrm{~km}$ to $16 \mathrm{~km}$ changes the $\mathrm{H}-1211$ tropospheric lifetime from $25.6 \mathrm{yr}$ to $24.6 \mathrm{yr}$, the $\mathrm{H}-2402$ lifetime from 42.9 to $39.1 \mathrm{yr}$ and the H-1202 lifetime from 3.1 to $2.9 \mathrm{yr} . \mathrm{H}-1301$ has a tropospheric lifetime greater than $10000 \mathrm{yr}$ for all studied tropopause heights. The tropospheric lifetime of H-1211 calculated here, 25-26 yr, agrees reasonably with the value of $23 \mathrm{yr}$ calculated by Burkholder et al. (1991), while that of H-2402 is slightly higher (39-43 versus $<34 \mathrm{yr}$ ) and that of $\mathrm{H}-1202$ slightly lower (2.9-3.1 versus $3.2 \mathrm{yr}$ ), compared to Burkholder et al. (1991).

Adjusting the photolysis rates by $20 \%$ has a relatively large effect on the tropospheric lifetimes, giving a tropospheric lifetime range for $\mathrm{H}-1211$ of $21.0 \mathrm{yr}$ to $30.9 \mathrm{yr}$, for $\mathrm{H}-2402$ of 34.0 to $50.8 \mathrm{yr}$ and for H-1202 lifetime of 2.5 to $3.7 \mathrm{yr}$.

\subsection{Stratospheric lifetimes}

To calculate the stratospheric lifetimes $\left(\tau_{\text {strat }}\right)$ in the model, the photolysis and $\mathrm{OH}$ sinks were only active in the stratosphere and the effect of a range of values for $F$ (the ratio of the mixing ratio of the molecule above the model domain $(25 \mathrm{~km})$ to that in the top box (centred on $23 \mathrm{~km})$ ) was investigated (Table 3 ). The stratospheric lifetime calculated in this way is an approximation since the atmospheric burden above the model domain is not known and so cannot be included in the calculation. However, use of a 1-D atmospheric model extending up to $50 \mathrm{~km}$ suggests that this is less than $1.5 \%$ of the total atmospheric burden for H-1211 and H-1301 at steady state with no tropospheric loss.

The stratospheric lifetimes calculated using the full range of possible values for $F$ are presented in Table 3. The value of $F$ can, however, be compared to actual measurements of the halons at 23 and $25 \mathrm{~km}$. Very few such measurements at these altitudes exist, but we do have measurements from three midlatitude balloon flights - two from Aire sur l'Adour, France, in October 1994 and March 1999, and one from Gap, France, in June 1997 - and a tropical balloon flight from Teresina, Brazil. The mid-latitude data are previously unpublished, but were collected and analysed in essentially identical manner to other balloon flights from the same series reported by Pfeilsticker et al. (2000). The tropical measurements were reported by Laube et al. (2008). For H-1211, based on three flights, the mean value of $F$ for H-1211 was 0.21 with a standard deviation of 0.01 . For H-1301, based on four flights, the mean value of $F$ was 0.74 with a standard deviation of 0.1 . For H-2402 only one flight detected the molecule above $25 \mathrm{~km}$ and gave a value for $F$ of 0.19 . H-1202 was not detected above $25 \mathrm{~km}$ on any of the flights.

The stratospheric steady-state lifetimes of H-1211 and H1301 have recently been re-evaluated by Laube et al. (2013) based on tracer analysis, using samples collected by the highaltitude research aircraft, M55 Geophysica, and a range of balloon flights. Laube et al. (2013) applied a relative method to calculate stratospheric lifetimes using CFC-11 as a reference tracer. For this method the stratospheric lifetime of CFC-11 must be known, and Laube et al. (2013) derived two sets of halon lifetimes relative to a CFC-11 lifetime of $45 \mathrm{yr}$ (as recommended in Montzka et al., 2011) and of $60.1 \mathrm{yr}$. The latter is justified as recent work has suggested a steady-state lifetime of 56-64 yr (Douglass et al. 2008). This is acknowledged in Montzka et al. (2011) as they note that "evidence is emerging that the lifetimes for some important ODSs (e.g., CFC-11) may be somewhat longer than reported in past assessments". As shown in Table 4 we here use the stratospheric halon lifetimes reported in Laube et al. (2013) relative to a CFC-11 lifetime of $60.1 \mathrm{yr}$, i.e. $36(32-41) \mathrm{yr}$ for $\mathrm{H}-1211$ and 82 (75-93) yr for H-1301.

The value of the ratio $F$ required to be used in the model to give the stratospheric lifetimes from Laube et al. (2013) was examined. For H-1211 a value of 0.65 was required, and for $\mathrm{H}-1301$ a value of 0.828 . For $\mathrm{H}-1301$ this is within the $1 \sigma$ range of the balloon measurements reported here. For $\mathrm{H}-$ 1211 this is outside the $1 \sigma$ range, but it is noted that a value for $F$ of 0.2 , as suggested by the balloon data, gives a stratospheric lifetime of $31 \mathrm{yr}$; this is in between the two lifetimes (based on a CFC-11 lifetime of 45 and $60.1 \mathrm{yr}$ ) reported by Laube et al. (2013).

There have been no stratospheric lifetimes derived from measurements for $\mathrm{H}-2402$ or $\mathrm{H}-1202$. Consequently the value of $F$ used for the estimate of the stratospheric lifetime 
Table 4. Tropospheric $\left(\tau_{\text {trop }}\right)$, stratospheric $\left(\tau_{\text {strat }}\right)$, and total atmospheric $\left(\tau_{\mathrm{atm}}\right)$ lifetimes of the halons reported in the literature and calculated in this work.

\begin{tabular}{|c|c|c|c|c|}
\hline Reference & H-1211 & H-1301 & H-2402 & H-1202 \\
\hline & \multicolumn{4}{|c|}{$\tau_{\text {trop }}(\mathrm{yr})$} \\
\hline Burkholder et al. (1991) & 23 & $>397$ & $<34$ & 3.2 \\
\hline \multirow[t]{3}{*}{ This work $^{\mathrm{a}}$} & 25 & $>10000$ & 41 & 3.0 \\
\hline & $(21-31)$ & $(-)$ & $(34-51)$ & $(2.5-3.7)$ \\
\hline & \multicolumn{4}{|c|}{$\tau_{\text {strat }}(\mathrm{yr})$} \\
\hline Volk et al. (1997) & $26 \pm 5$ & - & - & - \\
\hline Laube et al. $(2013)^{b}$ & $27(+4,-3)$ & $62(+7,-6)$ & - & - \\
\hline Laube et al. $(2013)^{\mathrm{c}}$ & $36(+5,-4)$ & $82(+11,-7)$ & - & - \\
\hline \multirow[t]{3}{*}{ This work } & $36(+5,-4)^{d}$ & $82(+11,-7)^{d}$ & $31^{\mathrm{e}}$ & $21^{\mathrm{e}}$ \\
\hline & $(32-41)$ & (75-93) & $(29-34)^{\mathrm{f}}$ & $(19-23)^{f}$ \\
\hline & \multicolumn{4}{|c|}{$\tau_{\mathrm{atm}}(\mathrm{yr})$} \\
\hline Burkholder et al. (1991) & 16 & 65 & $<20$ & 3.3 \\
\hline Butler et al. (1998) & $11^{\mathrm{h}}$ & - & - & - \\
\hline Papanastasiou et al. $(2013)^{\mathrm{i}}$ & 16.4 & - & 28.3 & 2.52 \\
\hline NASA/JPL ${ }^{j}$ & 13.5 & - & 14.1 & 2.08 \\
\hline \multirow[t]{2}{*}{ This work ${ }^{\mathrm{a}, \mathrm{d}}$} & 15 & $82^{\mathrm{k}}$ & 17 & 2.6 \\
\hline & $(13-18)$ & $(75-93)$ & $(16-20)$ & $(2.2-3.2)$ \\
\hline
\end{tabular}

\footnotetext{
a See Sect. 8 and Table 2 for further details.

b Based on a lifetime for CFC-11 of $45 \mathrm{yr}$.

${ }^{c}$ Based on a lifetime for CFC-11 of $60.1 \mathrm{yr}$.

$\mathrm{d}$ The stratospheric lifetimes of H-1211 and H-1301 from Laube et al. (2013) for a CFC-11 lifetime of $60.1 \mathrm{yr}$ are used.

of $\mathrm{H}-2402$ was constrained using the one relevant balloon flight. For H-1202 there are no relevant balloon flight data, but it seems likely that mixing ratios are decreasing rapidly with height at this height, and so a value for $F$ of 0.2 , as measured for $\mathrm{H}-1211$ and $\mathrm{H}-2402$, was used for the estimate of stratospheric lifetime.

\subsection{Total atmospheric lifetimes}

The total atmospheric lifetimes $\left(\tau_{\mathrm{atm}}\right)$ are calculated by combining the inverse of the tropospheric and stratospheric lifetimes. The tropospheric lifetimes used for the alternative total lifetimes are those calculated for $\mathrm{Z}_{\text {trop }}=14 \mathrm{~km}$. For H-1211 and $\mathrm{H}-1301$ the stratospheric lifetimes derived by Laube et al. (2013) relative to a CFC-11 lifetime of 60.1 yr were used. For H-2402 and H-1202 the stratospheric lifetimes calculated in the model, with the value of $F$ constrained by the balloon data as described above, were used.

This gives total atmospheric lifetimes of $15(13-18) \mathrm{yr}$ for H-1211, 82 (75-93) yr for H-1301, 17 (16-20) yr for H-2402, and $2.6(2.2-3.2) \mathrm{yr}$ for $\mathrm{H}-1202$. This is likely to be a maximum lifetime for $\mathrm{H}-2402$ since, unlike for $\mathrm{H}-1211$ and $\mathrm{H}$ 1202, Burkholder et al. (1991) did not extrapolate the absorption cross-sections to wavelengths longer than $320 \mathrm{~nm}$ due to the non-systematic nature of the cross-sections calculated between $300-320 \mathrm{~nm}$. Uncertainty ranges are calculated by combining the uncertainties in the tropospheric and the stratospheric lifetimes given in Table 4. Note that the uncertainties in the stratospheric lifetimes do not take account of the uncertainty in the choice of lifetime of CFC-11 used.

\subsection{Effects on cumulative emissions and banks}

The top-down emissions of H-1211, H-1301 and H-2402 derived in Sect. 4 would be altered by the alternative lifetimes reported in Sect. 8. The decreased lifetimes of $\mathrm{H}-1211$ and $\mathrm{H}-$ 2402, compared to those reported in Montzka et al. (2011), would require higher global emissions to fit the measurements. Likewise the increased lifetime of $\mathrm{H}-1301$ would require lower emissions to fit the measurements. The model 
Table 5. The effect of using different CFC-11 lifetimes to calculate the stratospheric lifetime of H-1211 and H-1301 (using the Laube et al. (2013) method - Sect. 8.2) on the total lifetimes, cumulative emissions and remaining banks of H-1211 and H-1301.

\begin{tabular}{ccccccc}
\hline \multicolumn{3}{c}{$\mathrm{H}-1211$} & \multicolumn{3}{c}{$\mathrm{H}-1301$} \\
\hline $\begin{array}{c}\tau_{\mathrm{CFC}-11} \\
(\mathrm{yr})\end{array}$ & $\begin{array}{c}\tau_{\mathrm{H}-1211} \\
(\mathrm{yr})\end{array}$ & $\begin{array}{c}\text { Cumulative } \\
\text { emissions } \\
(\mathrm{Gg})\end{array}$ & $\begin{array}{c}\text { Bank } \\
(\mathrm{Gg})\end{array}$ & $\begin{array}{c}\tau_{\mathrm{H}-1301} \\
(\mathrm{yr})\end{array}$ & $\begin{array}{c}\text { Cumulative } \\
\text { emissions } \\
(\mathrm{Gg})\end{array}$ & $\begin{array}{c}\text { Bank } \\
(\mathrm{Gg})\end{array}$ \\
\hline 45 & 13 & 319 & -5 & 62 & 107 & 42 \\
52.5 & 14 & 304 & 10 & 72 & 104 & 45 \\
60.1 & 15 & 290 & 24 & 82 & 101 & 48 \\
\hline
\end{tabular}

was run with the alternative lifetimes; the cumulative emissions (1963-2010) derived for H-1211 increased by $14 \mathrm{Gg}$ to $290 \mathrm{Gg}$, for $\mathrm{H}-1301$ they decreased by $5 \mathrm{Gg}$ to $101 \mathrm{Gg}$ and for $\mathrm{H}-2402$ they increased by $4 \mathrm{Gg}$ to $46 \mathrm{Gg}$ (Table 2).

These alternative cumulative emissions have implications for the estimates of the banks. Calculating the banks using the alternative cumulative emissions would mean that the $\mathrm{H}$ 1211 bank was $24 \mathrm{Gg}, 63 \%$ lower than that estimated by HTOC, and the H-1301 bank would be $48 \mathrm{Gg}$ compared to $43 \mathrm{Gg}$ estimated by HTOC (Table 2). The cumulative emissions of H-2402 would be $4 \mathrm{Gg}$ higher, but this cannot be directly compared to the bank reported by HTOC as they do not report production of $\mathrm{H}-2402$ and their estimate of the bank is not a direct calculation of production less emissions.

The estimate of $24 \mathrm{Gg}$ for the remaining H-1211 bank suggests that at current annual emission rates $(5.7$ and $5.0 \mathrm{Gg}$ in 2009 and 2010) the bank of H-1211 would be used up within the next five years. Given the current estimated rate of emissions it seems unlikely that the bank is so small. If we had used the lower limit of the uncertainty range of the atmospheric lifetime for H-1211 (i.e. $13 \mathrm{yr}$, see Table 4 and Sect. 8.3), the derived cumulative emissions would have been greater than the reported production giving a bank of $-5 \mathrm{Gg}$ (Table 2). The effect of the uncertainties in the stratospheric lifetime of $\mathrm{H}-1211$ reported by Laube et al. (2013) (based on assuming different lifetimes for CFC-11) are not considered in the uncertainty ranges quoted in Table 2 , but they are shown separately in Table 5. It should be noted that our alternative estimate of the atmospheric lifetime of $\mathrm{H}$ 1211 uses the stratospheric lifetime of H-1211 derived using the longer CFC-11 lifetime of $60.1 \mathrm{yr}$ given in Laube et al. (2013), and had we chosen the stratospheric lifetime of $\mathrm{H}$ 1211 of $27 \mathrm{yr}$ determined by Laube et al. (2013) for a CFC-11 lifetime of $45 \mathrm{yr}$, this would also have given an atmospheric lifetime of $13 \mathrm{yr}$ and again led to a negative value for the calculated bank. It is interesting to note that a recent study (Papanastasiou et al., 2013) found that, using new absorption cross-section data for $\mathrm{H}-1211$ in the wavelength range 300$350 \mathrm{~nm}$, a lifetime of $16.4 \mathrm{yr}$ for $\mathrm{H}-1211$ was calculated compared to $13.5 \mathrm{yr}$ when the absorption cross-section data from earlier studies (Sander et al., 2011) were used. Clearly large uncertainties in the lifetime of $\mathrm{H}-1211$ remain, and these af- fect top-down estimates of the emissions and subsequently the size of the remaining banks. However, it should be noted that atmospheric lifetimes of H-1211 of 14 yr or less are unlikely to be consistent with the reported cumulative production, and would therefore raise the question as to the accuracy of the reported production.

For H-1301, using the atmospheric lifetime of $82 \mathrm{yr}$ (CFC11 lifetime $=60.1 \mathrm{yr}$ ) gives a bank $13 \%$ larger than that estimated by HTOC, which has implications for the decline of tropospheric bromine (see below). The effect of using a shorter CFC-11 lifetime for determination of the H-1301 lifetime is shown in Table 5. This tends to bring the estimated cumulative emissions and bank closer to those estimated by HTOC.

The recent study of Papanastasiou et al. (2013) reports a lifetime of $28.3 \mathrm{yr}$ for $\mathrm{H}-2402$, which is longer than previous estimates of less than $20 \mathrm{yr}$. Using a lifetime of $28.3 \mathrm{yr}$ to derive top-down estimates of the emissions, we calculate the cumulative (1963-2010) emissions of H-2402 to be $35 \mathrm{Gg}$ compared to the $42 \mathrm{Gg}$ we derived using a lifetime of $20 \mathrm{yr}$ and $46 \mathrm{Gg}$ using a lifetime of $17 \mathrm{yr}$. This longer lifetime would imply considerably smaller emissions of $\mathrm{H}-2402$ from Russia and the former Soviet Union, where it was almost exclusively produced.

\subsection{Effects on total tropospheric bromine}

Figure $3 \mathrm{~b}$ also shows (dashed dot line) the extrapolation to 2060 of the halons' contribution to total tropospheric bromine, using release fractions based on the banks calculated from our top-down cumulative emissions derived using the alternative atmospheric lifetimes given in Table 4 . These bank release fractions were calculated by dividing emissions of the halon in 2010 by the calculated bank at the end of 2009 (H-1211-0.18, H-1301-0.055). For H-2402 the same bank and bank release fractions are used as used in the scenarios plotted in Fig. 3b because a revised bank cannot be calculated since no production data have been reported.

With an even smaller H-1211 bank than in the other scenarios presented in Fig. 3b, the tropospheric bromine burden from the halons is predicted to initially fall more quickly in the coming decades, but by 2060 all three scenarios converge. 
H-1301 contributes $50 \%$ even earlier, in 2017. With the larger H-1301 bank, H-1301 is calculated to contribute almost $95 \%$ of the total bromine from the halons in 2060.

\section{Conclusions}

The atmospheric mixing ratios of $\mathrm{H}-1202, \mathrm{H}-1211$ and $\mathrm{H}-$ 2402 are all declining and are likely to continue to do so due to the cessation of all halon production in 2010 . H1301 mixing ratios are still growing. The total contribution of the halons to tropospheric bromine at Cape Grim peaked at $8.1 \mathrm{ppt}$ in 2007-2008 and has since declined to $7.9 \mathrm{ppt}$ in mid-2011. H-1301 is likely to become the main halon contributing to tropospheric bromine by 2025 . The total contribution to tropospheric bromine from the halons in 2060 is predicted to be about $3.0 \mathrm{ppt}, 38 \%$ of that in 2010 .

Emissions of all of the halons have declined since peaking in the late 1980s to mid-1990s, but the decline has slowed in recent years with no significant changes in emissions of H-1301 and H-2402 between 2006 and 2010.

H-1202 emissions appear not to have declined to zero as would be expected if they occurred during $\mathrm{H}-1211$ production. The exact reason for this is unknown, but it could be due to unreported $\mathrm{H}-1211$ production. Alternatively, it could be due to some of the $\mathrm{H}-1202$ that was produced as a by-product of $\mathrm{H}-1211$ production, having been captured and installed in military aircraft, creating a H-1202 bank from which emissions are continuing. Another possibility could be contamination of existing stocks of H-1211 with H-1202. This requires verification by analysis of stocks of $\mathrm{H}-1211$, but, if this were the case, future emissions of $\mathrm{H}-1202$ might be expected to follow the same trend of those of H-1211.

Alternative atmospheric lifetimes for the halons are calculated based on recently reported new stratospheric lifetimes. These are $15 \mathrm{yr}$ for $\mathrm{H}-1211,82 \mathrm{yr}$ for $\mathrm{H}-1301,17 \mathrm{yr}$ for $\mathrm{H}-$ 2402 and $2.6 \mathrm{yr}$ for H-1202. Using these alternative lifetimes, new top-down estimates of the emissions are derived. For $\mathrm{H}$ 1301 these imply that the 2010 bank is $48 \mathrm{Gg}, 13 \%$ larger than estimated by HTOC, which could delay the decline in tropospheric bromine. For H-1211, this leads to a calculated bank of $24 \mathrm{Gg}, 63 \%$ smaller than estimated by HTOC. With estimated current emission rates, a bank of this size would be rapidly exhausted, quickening the decline in tropospheric bromine. However, this discrepancy with the HTOC estimate of the bank, and uncertainties in the lifetime of H-1211, suggest that considerable uncertainties in the $\mathrm{H}-1211$ budget remain, which require further investigation.

\section{Supplementary material related to this article is available online at: http://www.atmos-chem-phys.net/13/ 5551/2013/acp-13-5551-2013-supplement.zip.}

Acknowledgements. The modelling work in this paper has been funded through a PhD studentship (Newland) tied to the NERC project "A Century-long Record of Trace Gases in the Northern Hemisphere from the NEEM Ice Core Drilling Project in Greenland" (NE/F021194/1). The measurements were supported by the European Commission (Project No. 226224: SHIVA) and the UK's Natural Environment Research Council (NERC), the latter through the National Centre for Atmospheric Science (NCAS, Oram) and an Advanced Research Fellowship (NE/I021918/1, Laube). We would also like to thank the NOAA-ESRL Global Monitoring Division (S. Montzka) and AGAGE (PIs: R. Prinn, R. Weiss and S. O'Doherty) for provision of publicly available halon data. We would like to thank the Cape Grim/Bureau of Meteorology (BoM) staff, in particular the late L. Porter, for the collection of the Cape Grim Air Archive and UEA flask samples at Cape Grim, and CSIRO staff (R. Langenfelds, P. Steele) for the collection of the UEA sub-samples of the Archive at CSIRO. We also gratefully acknowledge A. Engel and U. Schmidt of the Johann Wolfgang Goethe Universität Frankfurt, the balloon team of the French Centre National d'Etudes Spatiales, and the succession of European Union-funded stratospheric research projects, for the stratospheric air sampling.

Edited by: J. B. Burkholder

\section{References}

AGAGE: available at: http://agage.eas.gatech.edu/data.htm, last access: 6 August 2012.

Atkinson, R., Baulch, D. L., Cox, R. A., Crowley, J. N., Hampson, R. F., Hynes, R. G., Jenkin, M. E., Rossi, M. J., Troe, J., and Wallington, T. J.: Evaluated kinetic and photochemical data for atmospheric chemistry: Volume IV - gas phase reactions of organic halogen species, Atmos. Chem. Phys., 8, 4141-4496, doi:10.5194/acp-8-4141-2008, 2008.

Burkholder, J. B., Wilson, R. R., Gierczak, T., Talukdar, R., McKeen, S. A., Orlando, J. L., Vaghijiani, G. L., and Ravishankara, A. R.: Atmospheric fate of $\mathrm{CBrF}_{3}, \mathrm{CBr}_{2} \mathrm{~F}_{2}$, and $\mathrm{CBrF}_{2} \mathrm{CBrF}_{2}, \mathrm{~J}$. Geophys. Res., 96, 5025-5043, doi:10.1029/90JD02735, 1991.

Butler, J. H., Montzka, S. A., Clarke, A. D., Lobert, J. M., and Elkins, J. W.: Growth and distribution of halons in the atmosphere, J. Geophys. Res., 103, 1503-1511, doi:10.1029/97JD02853, 1998.

Butler, J. H., Battle, M., Bender, M. L., Montzka, S. A., Clarke, A. D., Saltzman, E. S., Sucher, C. M., Severinghaus, J. P., and Elkins, J. W.: A record of atmospheric halocarbons during the twentieth century from polar firn air, Nature, 399, 749-755, 1999.

Daniel, J. S., Velders, G. J. M. (coordinating lead authors), Douglass, A. R., Forster, P. M. D., Hauglustaine, D. A., Isaksen, I. S. A., Kuijpers, L. J. M., McCulloch, A., Wallington, T. J., Ashford, P., Montzka, S. A., Newman, P. A., and Waugh, D. W.: Scientific Assessment of Ozone Depletion: 2010, Global Ozone Research and Monitoring Project, Report No. 52, 516 pp., Chapter 5, Halocarbon scenarios, ozone depletion potentials, and global warming potentials, World Meteorological Organization, Geneva, Switzerland, 2007.

Douglass, A. R., Stolarski, R. S., Schoeberl, M. R,. Jackman, C. H., Gupta, M. L,. Newman, P. A., Nielsen, J. E., and Flem- 
ing, E. L., Relationship of loss, mean age of air and the relationship of CFCs to stratospheric circulation and implications for atmospheric lifetimes, J. Geophys. Res., 113, D14309, doi:10.1029/2007JD009575, 2008.

Fraser, P. J., Langenfelds, R., Derek, N., and Porter, L.: Studies in air-archiving techniques, 1 , Long term stability of atmospheric trace gases in dry, natural air stored in high pressure, surface treated aluminium cylinders, in Baseline 89, edited by: Wilson, S. and Gras, J., 16-29, Bur. Meteorol. and CSIRO Atmos. Res., Melbourne, Victoria, Australia, 1991.

Fraser, P. J., Oram, D. E., Reeves, C. E., Penkett, S. A. and McCulloch, A.: Southern hemispheric halon trends (1978-1998) and global halon emissions, J. Geophys. Res., 104, 15985-15999, doi:10.1029/1999JD900113, 1999.

Gillotay, D. and Simon, P. C.: Ultraviolet absorption spectrum of bromotrifluoromethane, dibromodifluoromethane and bromochlorodifluoromethane in the vapour phase, J. Atmos. Chem., 8, 41-62, 1989.

Gillotay, D., Simon, P. C., and Dierickx, L.: Temperature dependence of ultraviolet abosorption cross-sections of brominated methanes and ethanes, Aeron. Acta, 335, 1-17, 1988.

Hough, A. M.: Development of a two-dimensional global tropospheric model: Model chemistry, J. Geophys. Res., 96, 73257362, doi:10.1029/90JD01327, 1991.

HTOC (Halon Technical Options Committee): Assessment Report of the Halon Technical Options Committee 1991, Ozone Secretariat, UNEP, Nairobi, Kenya, 1991.

HTOC (Halon Technical Options Committee): Assessment Report of the Halon Technical Options Committee 1998, Ozone Secretariat, UNEP, Nairobi, Kenya, 1999.

HTOC (Halon Technical Options Committee): Assessment Report of the Halon Technical Options Committee 2010, Ozone Secretariat, UNEP, Nairobi, Kenya, 2011.

Langenfelds, R. J., Fraser, P. J., Francey, R. J., Steele, L. P., Porter, L. W., and Allison, C. E.: The Cape Grim air archive: The first seventeen years, in Baseline 94-95, edited by: Francey, R. J., Dick, A. L., and Derek, N., 53-70, Bur. Meteorol. and CSIRO Atmos. Res., Melbourne, Victoria, Australia, 1996.

Laube, J. C., Engel, A., Bönisch, H., Möbius, T., Worton, D. R., Sturges, W. T., Grunow, K., and Schmidt, U.: Contribution of very short-lived organic substances to stratospheric chlorine and bromine in the tropics - a case study, Atmos. Chem. Phys., 8, 7325-7334, doi:10.5194/acp-8-7325-2008, 2008.

Laube, J. C., Martinerie, P., Witrant, E., Blunier, T., Schwander, J., Brenninkmeijer, C. A. M., Schuck, T. J., Bolder, M., Röckmann, T., van der Veen, C., Bönisch, H., Engel, A., Mills, G. P., Newland, M. J., Oram, D. E., Reeves, C. E., and Sturges, W. T.: Rapid growth of HFC-227ea (1,1,1,2,3,3,3Heptafluoropropane) in the atmosphere, Atmos. Chem. Phys., 10, 5903-5910, doi:10.5194/acp-10-5903-2010, 2010.

Laube, J. C., Hogan, C., Newland, M. J., Mani, F. S., Fraser, P. J., Brenninkmeijer, C. A. M., Martinerie, P., Oram, D. E., Röckmann, T., Schwander, J., Witrant, E., Mills, G. P., Reeves, C. E., and Sturges, W. T.: Distributions, long term trends and emissions of four perfluorocarbons in remote parts of the atmosphere and firn air, Atmos. Chem. Phys., 12, 4081-4090, doi:10.5194/acp-12-4081-2012, 2012.

Laube, J. C., Keil, A., Bönisch, H., Engel, A., Röckmann, T., Volk, C. M., and Sturges, W. T.: Observation-based assessment of stratospheric fractional release, lifetimes, and ozone depletion potentials of ten important source gases, Atmos. Chem. Phys., 13, 2779-2791, doi:10.5194/acp-13-2779-2013, 2013.

McCulloch, A.: Global production and emissions of bromochlorodifluoromethane and bromotrifluoromethane (halons 1211 and 1301), Atmos. Environ., Part A, 26, 1325-1329, 1992.

Montzka, S. A. and Elkins, J. W.: NOAA/ESRL/GMD halons flask data, Versions 2012-07-09 (H-1301) and 2012-07-16 (H-1211 and $\mathrm{H}-2402)$, available at ftp://ftp.cmdl.noaa.gov/hats/halons/ flasks/, last access: August 2012.

Montzka, S. A., Fraser, P. J. (coordinating lead authors), Butler, J. H., Connell, P. S., Cunnold, D. M., Daniel, J. S., Derwent, R. G., Lal, S., McCulloch, A., Oram, D. E., Reeves, C. E., Sanhueza, E., Steele, L. P., Velders, G. J. M., Weiss, R. F., and Zander, R. J.: Scientific Assessment of Ozone Depletion: 2002, Global Ozone Research and Monitoring Project, Report No. 47, Chapter 1, Controlled Substances and Other Source Gases, World Meteorological Organization, Geneva, Switzerland, 2003.

Montzka, S. A., Reimann, S. (coordinating lead authors), Engel, A., Krüger, K., O’Doherty, S., Sturges, W., Blake, D., Dorf, M., Fraser, P., Froidevaux, L., Jucks, K., Kreher, K., Kurylo, M., Mellouki, A., Miller, J., Nielsen, O.-J., Orkin, V., Prinn, R., Rhew, R., Santee, M., Stohl, A., and Verdonik, D.: Scientific Assessment of Ozone Depletion: 2010, Global Ozone Research and Monitoring Project, Report No. 52, 516 pp., Chapter 1, Ozone-Depleting Substances (ODSs) and Related Chemicals, World Meteorological Organization, Geneva, Switzerland, 2011.

Oram, D. E., Mani, F. S., Laube, J. C., Newland, M. J., Reeves, C. E., Sturges, W. T., Penkett, S. A., Brenninkmeijer, C. A. M., Röckmann, T., and Fraser, P. J.: Long-term tropospheric trend of octafluorocyclobutane (c- $\mathrm{C}_{4} \mathrm{~F}_{8}$ or PFC-318), Atmos. Chem. Phys., 12, 261-269, doi:10.5194/acp-12-261-2012, 2012.

Papanastasiou, D. K., Carlon, N. R., Neuman, J. A., Fleming, E. L., Jackman, C. H., and Burkholder, J. B.: Revised UV absorption spectra, ozone depletion potentials, and global warming potentials for the ozone-depleting substances $\mathrm{CF}_{2} \mathrm{Br}_{2}$, $\mathrm{CF}_{2} \mathrm{ClBr}$, and $\mathrm{CF}_{2} \mathrm{BrCF}_{2} \mathrm{Br}$, Geophys. Res. Lett., 40, 464-469, doi:10.1002/grl.50121, 2013.

Pfeilsticker, K., Sturges, W. T., Bösch, H., Camy-Peyret, C., Chipperfield, M. P., Engel, A., Fitzenberger, R., Müller, M., Payan, S., and Sinnhuber, B., M-.: Lower stratospheric organic and inorganic bromine budget for the Arctic winter 1998/99, Geophys. Res. Lett., 27, 3305-3308, doi:10.1029/2000GL011650, 2000.

Plumb, A. and Mahlman, J. D.: The zonally-averaged transport characteristics of the GFDL general circulation/transport model, J. Atmos. Sci., 44, 298-327, 1987.

Prinn, R. G., Weiss, R. F., Fraser, P. J., Simmonds, P. G., Cunnold, D. M., Alyea, F. N., O’Doherty, S., Salameh, P., Miller, B. R., Huang, J. R., Wang, H. J., Hartley, D. E., Harth, C., Steele, L. P., Sturrock, G. A., Midgley, P. M., and McCulloch, A.: A history of chemically and radiatively important gases in air deduced from ALE/GAGE/AGAGE, J. Geophys. Res., 105, 1775117792, doi:10.1029/2000JD900141, 2000.

Reeves, C. E., Sturges, W. T., Sturrock, G. A., Preston, K., Oram, D. E., Schwander, J., Mulvaney, R., Barnola, J.-M., and Chappellaz, J.: Trends of halon gases in polar firn air: implications for their emission distributions, Atmos. Chem. Phys., 5, 2055-2064, doi:10.5194/acp-5-2055-2005, 2005. 
Sander S. P., Gillotay, D., Hampson, R. F., Magid, H., Nielsen, O. J., Ravishankara, A. R., and Simon, P. C.: Laboratory studies of halocarbon loss processes, in Report on Concentrations, Lifetimes and Trends of CFCs, Halons and Related Species, NASA Ref, Publ., 1339, 4.1-4.17, 1994.

Sander, S. P., Friedl, R. R., Abbatt, J. P. D., Barker, J. R., Burkholder, J. B., Golden, D. M., Kolb, C. E., Kurylo, M. J., Moortgat, G. K., Wine, P. H., Huie, R. E., and Orkin, V. L.: Chemical kinetics and photochemical data for use in atmospheric studies, evaluation number 17, JPL Publ. 10-6, 4G-33, 2011.

Sturrock, G. A., Etheridge, D. M., Trudinger, C. M., Fraser, P. J., and Smith, A. M.: Atmospheric histories of halocarbons from analysis of Antarctic firn air: major Montreal Protocol species, J. Geophys. Res., 107, 4765, doi:10.1029/2002/JD002548, 2002.
Volk, C. M., Elkins, J. W., Fahey, D. W., Sutton, G. S., Gilligan, J. M., Loewenstein, M., Podolske, J. R., Chan, K. R., and Gunson, M. R.: Evaluation of source gas lifetimes from stratospheric observations, J. Geophys. Res., 102, 25543-25564, doi:10.1029/97JD02215, 1997.

Weeks, I., Francey, R., Beardsmore, D., and Steele, L. P.: Studies in air archiving techniques, 2, Filling high pressure cylinders with baseline air, in Baseline 90, pp. 16-23, edited by S. Wilson and J. Gras, Bur. Meteorol. And CSIRO Atmos. Res., Melbourne, Victoria, Australia, 1992 